\title{
Biogas Plant Modelling for Flexibility Provision in the Power System of Bornholm Island
}

Zepter, Jan Martin Wilhelm; Gabderakhmanova, Tatiana; Andreasen, Karl Maribo; Boesgaard, Knud; Marinelli, Mattia

\section{Published in:}

Proceedings of the $55<$ sup $>$ th $</$ sup $>$ International Universities Power Engineering Conference 2020

Link to article, DOI:

10.1109/UPEC49904.2020.9209808

Publication date:

2020

Document Version

Peer reviewed version

Link back to DTU Orbit

Citation (APA):

Zepter, J. M. W., Gabderakhmanova, T., Andreasen, K. M., Boesgaard, K., \& Marinelli, M. (2020). Bipgas Plant Modelling for Flexibility Provision in the Power System of Bornholm Island. In Proceedings of the 55

International Universities Power Engineering Conference 2020 IEEE.

https://doi.org/10.1109/UPEC49904.2020.9209808

\section{General rights}

Copyright and moral rights for the publications made accessible in the public portal are retained by the authors and/or other copyright owners and it is a condition of accessing publications that users recognise and abide by the legal requirements associated with these rights.

- Users may download and print one copy of any publication from the public portal for the purpose of private study or research.

- You may not further distribute the material or use it for any profit-making activity or commercial gain

- You may freely distribute the URL identifying the publication in the public portal 


\title{
Biogas Plant Modelling for Flexibility Provision in the Power System of Bornholm Island
}

\author{
Jan Martin Zepter*, Tatiana Gabderakhmanova*, Karl Maribo Andreasen ${ }^{\dagger}$, \\ Knud Boesgaard ${ }^{\dagger}$, Mattia Marinelli* \\ * Department of Electrical Engineering \\ Technical University of Denmark (DTU) \\ Ris $\varnothing$ campus, Roskilde, Denmark \\ \{jmwze, tatigab, matm $\} @$ elektro.dtu.dk \\ $\dagger$ Fremsyn ApS \\ Kgs. Lyngby, Denmark \\ $\{$ karl, knud $\} @$ fremsyn.net
}

\begin{abstract}
Biogas power plants play a vital role in the structure of integrated energy systems to further decarbonize the energy sector. On the one hand, they can facilitate the broad integration of variable renewable energy sources; on the other, they directly interlink different energy domains and provide multi-energy services. This paper provides an overview on the possibilities and potentials of biogas power plants in providing flexibility towards islanded power systems. To this end, we present a model that includes the most relevant dynamics from an electrical engineering perspective. For a given infeed of raw material, it is able to characterize the anaerobic digestion processes and quantify the energy output in order to evaluate the plant's flexibility potential. The model is validated against real data from a 3-MW biogas power plant on the island of Bornholm, Denmark. The results show that actual on-site measurements in terms of biogas production as well as electrical and thermal output may be matched by the presented model. Furthermore, the paper gives a detailed overview on the estimated biomass potential of the island of Bornholm, as well as the flexibility assessment of the entailed biogas operations.
\end{abstract}

Index Terms-biogas, CHP, flexibility, multi-energy system

\section{INTRODUCTION}

Over the last two decades, the power systems around the world were exposed to disruptive changes in their structure. Predominantly due to climate concerns, the power generation shifted away from fossil-fueled thermal generators towards less carbon-intensive renewable energy sources such as wind and solar PV, leading to their large-scale deployment. These sources, however, inherit a natural variability in their power generation due to changing and only partly predictable weather conditions - $\mathrm{a}$ fact that increases the need for more flexibility in future power systems. Biogas power plants might be able to stand up to these flexibility needs by providing dispatchable generation while reducing associated greenhouse gas emissions in comparison to other fossil fuel-based technologies.

Along with the increased penetration of variable energy sources, biogas power plants have been subject to growth in

This work has received funding from the H2020 INSULAE project under the Grant Agreement No. 824433. The goal of the project is to provide innovative energy solutions for decarbonising European islands. For more information, visit http://insulae-h2020.eu/.

\section{8-1-7281-1078-3/20/\$31.00 @2020 IEEE}

many countries for facilitating large shares of renewable generation [1]. In times of renewable underproduction, the generation of biogas power plants supplements the renewable generation, while in times of overproduction, biogas plants may take up additional load for their internal heating processes. With respect to a multi-energy system thinking, biogas plants contain even more flexibility potential that is as of today only rarely used: If not converted to electrical or thermal power, the produced biogas may be upgraded to biomethane that could in turn be used for gas grid injections or transportation means. In that sense, biogas plants play a vital role in further flexibilizing future renewable and integrated energy systems while reducing greenhouse gas emissions. The resources for a sustainable biogas production - the biomasses-however, have to be put to a proper use. It is a widely recognized perception that biogas should mainly be produced from recycled biomasses, i.e. for example animal manure, household wastes or other recycled products that would nonetheless emit their shares of carbon dioxide to the atmosphere.

Seen from a more holistic point of view, biogas power plants depict an exemplary case and integral part of a circular economy. As they digest residues from other industries-e.g. agriculture or household waste-and reuse them for power and heat generation, the utilization of fossil fuels and their associated greenhouse gas emissions can be significantly reduced. But not only with respect to upstream but also downstream production chains, biogas power plants spare natural resources. In the same way as they take up agricultural residues, they return digested materials which serve as fertilizer for the farmers' fields, reducing the need for chemicals and increasing the water absorption potential of the ground. In fact, degassed biomasses have higher nutritional values and are thus rather complementing than competing with direct field fertilization of manure.

The aim of this work is to provide a systemic overview on the dynamics and flexibility potentials of biogas power plants. Specifically, the paper addresses the question how much flexibility is contained in the internal biogas processes. To this end, the presented model aims at capturing and coupling the main dynamics of the different parts of a biogas 


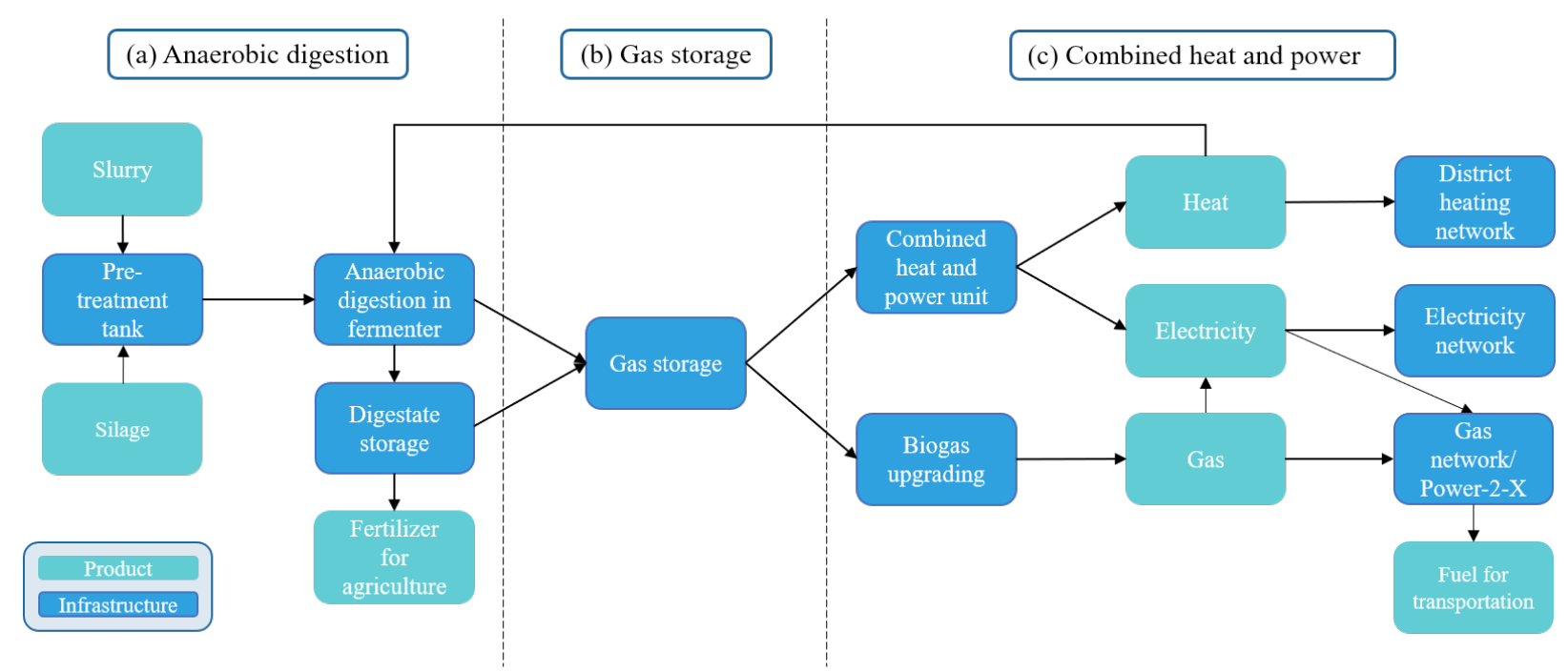

Fig. 1. Block diagram of a biogas combined heat and power plant.

plant. The coupled model is tailored to and validated against historical on-site energy measurements from a biogas power plant on Bornholm. For determining the flexibility potential for the wider (islanded) electrical system, it is necessary to incorporate all entailed operational processes. So far, only few models were designed for assessing the flexibility from biogas plants from a rather electrical and not specifically chemical perspective. For instance, the coupled processes of a biogasfueled microturbine are presented in [2], however, their model was not validated in terms of energy output with real-life data.

The remainder of the paper is structured as follows: Section II gives a detailed overview on the biomass potential on the island of Bornholm. Subsequently, Section III specifies the coupled modelling structure, while Section IV displays the simulation results. Section $\mathrm{V}$ concludes the paper.

\section{Biomass POTENTIAL ON BORNHOLM}

In islanded power systems with increasing shares of renewable generation, there is a large need for stabilizing the electric network and diminishing the dependency of the island on mainland grid connections [3]. In this regard, the biogas power plant on Bornholm becomes increasingly important with its flexibility in the gas storage and logistics operations. By 2035, the municipality of Bornholm targets to be an independent and fully renewable-powered island [4], yet relying as of today still to a large extent on the mainland connection to Sweden. For enhancing the role and for estimating the flexibility of local bio-based operations, this study examines the amount and energy potential of different biomass resources on the island. Table I presents an overview of the findings. The biogas plant on the island has currently a permission to treat about 120,000 tons of biowaste per year, whereas the total quantity that could potentially be used for biogas production is estimated to accumulate to 741,425 tons. Bornholm inherits thus a large unused biomass potential from local resources.
TABLE I

Potential AND ENERgy CONTENT OF BiOMASSES ON BORNHOLM

\begin{tabular}{lrr}
\hline Biomass & Potential [tons/year] & Energy content $[\mathrm{MWh}]$ \\
\hline Liquid manure & 547,536 & 70,908 \\
Straw & 88,480 & 157,500 \\
Wood chips & 50,000 & 25,105 \\
Deep litter & 29,731 & 17,592 \\
Garden waste & 8,920 & 4,479 \\
Other & 16,758 & 8,674 \\
\hline Total & 741,425 & 284,258 \\
\hline
\end{tabular}

Liquid manure from animal husbandry is in terms of quantity the most important resource for the biogas operations. Although having a low energy yield at generally $12-17 \mathrm{~m}^{3}$ methane per ton [6], it depicts the main carrier component for other biomasses in the basis operation of the plant. The full potential of manure (liquid manure and deep litter) is calculated based on the CHR-18 register [5], a central public database operated by Danish authorities to which all Danish farmers are obliged to report to once a year. Sixty farms on Bornholm have a biomethane potential above $5,000 \mathrm{Nm}^{3}$ per year which is assumed in this study as the lower limit for collecting manure with sufficient economic benefit. The full economically viable potential on Bornholm amounts to 547,536 tons of liquid manure and 29,731 tons of deep litter and solid manure. Compared to present state, a utilization of the full potential from manure-based biomasses would quadruple the biomethane production on the island. While manure is produced at a stable level year-round, it is rather unsuitable for seasonal storage, e.g. for shifting its utilization to winter months with higher energy demand.

The total straw potential on Bornholm is calculated based on the average yield over the last ten years from Danmarks Statistik. By converting straw into silage, the anaerobic gas potential may significantly be increased which can be ef- 
ficiently done in conjunction with other biomasses such as secondary crops [7]. Silage may be stored decentralized at the farmers' fields and its potential utilized during winter, thereby unleashing the possibility of seasonal variations in the biogas plant's production. The database indicates that more than half of the straw potential on the island is currently not utilized.

Data on garden waste and wood chips have been collected in cooperation with the municipality of Bornholm. These resources are currently being directly burned in local power plants (Hasle, Nexø, and Rønne), although they could possibly be used for biogas production with a potential of 8,920 and 50,000 tons per year, respectively. Other suitable biomasses comprise secondary crops and household wastes. By 2021, Bornholm starts sorting private household waste, thereby increasing the potentially usable biomass fraction in upcoming years. Similarly, the secondary crop production is likely increasing to combat high nitrate levels on the island.

The main constituents of the biomasses presently utilized in the biogas plant are cattle (approx. 75\%) and swine (approx. $15 \%)$ manure and slaughterhouse wastes, as well as other biowastes such as secondary crops (approx. 10\%).

\section{Biogas Plant Implementation in Simulink}

The presented biogas power plant model comprises four distinct processes with their specific dynamics: (a) the digestion of organic material under anaerobic conditions, (b) the storage of biogas, (c) the burning of gas for generating combined heat and power, and (d) the auxiliary self-consumption of the plant. Figure 1 visualizes the entailed processes of a biogas plant and their possible flexibility options in a block diagram. This section details the mathematical foundation of the model.

\section{A. Anaerobic Digestion Process Modelling}

Anaerobic digestion is the conversion process of organic material to biogas by the use of microbial bacteria. The digestion process can be described by four stages [8]-[10]:

(i) Hydrolysis, in which the polymeric components of the biomass are broken down by hydrolytic bacteria into simpler, soluble constituents such as sugars and fatty acids.

(ii) Acidogenesis (fermentation), in which the soluble organic matter from the hydrolysis is converted to alcohols and long-chain fatty acids. Hydrogen is produced in small amounts by the fermentation of sugars.

(iii) Acetogenesis, in which the volatile fatty acids are converted into methanogenic constituents, such as hydrogen and acetic acids.

(iv) Methanogenesis, in which the methanogenic constituents are converted to methane by utilizing hydrogenotrophic and aceticlastic bacteria.

The specific purpose of study defines the needed modelling complexity of these stages. The literature provides a range of different modelling approaches of the anaerobic digestion processes, of which a review is conducted in [11]. The most comprehensive and complete way to capture the biochemical reaction processes is the Anaerobic Digestion Model No. 1
(ADM1), as for example applied in [12]. However, the implementation of the ADM1 is not straightforward, which is why many approaches exist to solely represent the kinetics of the process, thereby aiming at simplifying the mathematical model of the anaerobic digestion significantly. From an electrical engineering perspective, it is necessary to describe the basic dynamics of the process in order to adequately capture the amount of biogas produced at a specific point in time. In this way, the electrical and the thermal output of the plant can be accurately modelled, and flexibility opportunities be analyzed.

TABLE II

Designated PARAMETERs AND Their VAlues.

\begin{tabular}{crl}
\hline Parameters & Value & Unit \\
\hline$\phi$ & 0.45 & $\mathrm{~m}^{3}$ biogas per $\mathrm{kg}$ volatile solids \\
$\mu_{m}$ & 0.05 & $\mathrm{~m}^{3}$ biogas per $\mathrm{kg}$ volatile solids and day \\
$\lambda$ & 4 & days \\
$\sigma_{\text {sto }}$ & 2500 & $\mathrm{~m}^{3}$ \\
$\theta$ & 9.67 & $\mathrm{kWh}^{3}$ per $\mathrm{m}^{3}$ methane \\
$\delta$ & 0.65 & $\mathrm{~m}^{3}$ methane per $\mathrm{m}^{3}$ biogas \\
\hline
\end{tabular}

The anaerobic digestion starts with the feeding of (liquid) manure or slurry, which is mostly given in wet weights due to the high water content. From the feed, however, only a volatile organic fraction of $5-15 \%$ is potentially digestible. The exact percentage depends on the specific composition of the feed, and especially on the vegetable co-substrate share that is used besides animal manure. The resulting biogas productivity correlates strongly with the biodegradable share of the slurry, i.e. it is connected to the percentage of organic matter per $\mathrm{kg}$ slurry [13].

The cumulative biogas yield $Y_{i}(t)$ from a specific feeding instance $i$ is in pertinent literature either described as a Monodkinetic [2] or as a modified Gompertz function [14], [15]. In this paper, the latter is used as characterized in (1).

$$
Y_{i}(t)=F_{i} \cdot \phi \cdot \exp \left(-\exp \left(\frac{\mu_{m} \cdot e}{\phi}(\lambda-t)+1\right)\right)
$$

where $F_{i}$ is the organic fraction of the biomass feed $i$ (in $\mathrm{kg}$ volatile solids), $\phi$ is the biogas potential, $\mu_{m}$ is the maximum biogas production rate, $e$ is Euler's number, and $\lambda$ is the input lag. Table II introduces these model parameters and their associated values.

The marginal biogas production rate $\dot{Y}_{i}(t)$ of a specific feed in the digestion process (in $\mathrm{m}^{3} / \mathrm{s}$ ) is then obtained by taking the first-order derivative of (1) with respect to time $t$, as performed in (2).

$$
\dot{Y}_{i}(t)=F_{i} \cdot \mu_{m} \cdot e \cdot \exp \left(\frac{\mu_{m} \cdot e}{\phi}(\lambda-t)+1-\exp \left(\frac{\mu_{m} \cdot e}{\phi}(\lambda-t)+1\right)\right)
$$

The resulting biogas production rate thus depends on the amount of volatile solids, the biogas production potential under mesophilic conditions (i.e. $38^{\circ} \mathrm{C}$, the influence of a change in temperature on the biogas production is neglected at this stage 
of the research), the maximum production rate per day, and the time the feed has remained in the digester since the feeding instance. The influence of inhibiting factors of the digestion process is incorporated in the parameterisation of the biogas production potential $\phi$ and the maximum daily production rate $\mu_{m}$ of a specific feed.

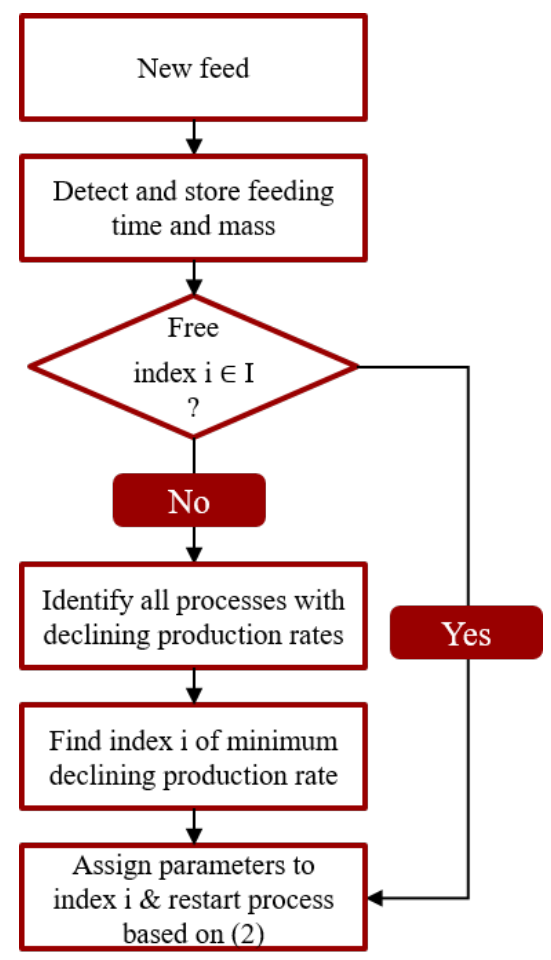

Fig. 2. Flow chart of the anaerobic digestion model.

The feeding frequency influences the process performance of the anaerobic digestion [16]. In this paper, a daily discrete feeding is implemented, which is based on historical data from the biogas plant on Bornholm. For each new feeding instance a biogas production rate following Eq. (2) is considered. A total number of $\mathcal{I}=15$ indices are maintained for the feedings. As these mainly take place throughout the workdays of a week, the provided indices effectively consider a single feeding over a three-week schedule, analogous to a hydraulic retention time of 21 days which is aligned to the data from the biogas plant. Subsequently, a feeding index is paired with a new feed if the residual biogas production rate of that index is the lowest of the ongoing processes. Figure 2 visualizes the different steps modelled within the anaerobic digestion process in a flow chart. The total biogas production of the plant $\dot{Y}_{t o t}$ is then composed of the sum of the ongoing separated production rates, as represented in (3).

$$
\dot{Y}_{t o t}(t)=\sum_{i \in \mathcal{I}} \dot{Y}_{i}(t)=\dot{Y}_{1}(t)+\dot{Y}_{2}(t)+\cdots+\dot{Y}_{15}(t)
$$

\section{B. Gas Storage Tank Modelling}

The gas storage of a biogas plant depicts the linking entity between the biogas production from the anaerobic digestion and the burning of biogas for the generation of combined heat and power. The biogas storage therewith represents the most easily realizable flexibility potential of a biogas plant as the size of the storage directly enhances the operational flexibility. While the plant's storage capacity is currently sized at $2500 \mathrm{~m}^{3}$, a maximum storage weight of 10 tons is imposed by Danish law based on EU's Seveso directive (2012/18/EU).

The gas storage level $L_{t}$ in percentage of the storage tank capacity $\sigma_{\text {sto }}$ is depending on the biogas influx from the anaerobic digestion process, i.e. the biogas production rate $\dot{Y}_{i}(t)$, and the outflow $O(t)$ towards the CHP units, i.e. the amount of biogas drawn by the generators to fulfill a certain electrical setpoint. The dynamics of the gas storage level can hence be represented by (4).

$$
L(t)=\frac{1}{\sigma_{\text {sto }}} \int_{t} \dot{Y}_{i}(t)-O(t) d t
$$

With $\theta$ being the energy content of biogas (in $\mathrm{kWh}$ per $\mathrm{m}^{3}$ methane) and $\delta$ the share of methane in a $\mathrm{m}^{3}$ of biogas, the outflow from the storage tank to the CHP units $O(t)$ is defined as in (5).

$$
O(t)=\frac{P_{e l}(t)}{\eta_{e l} \cdot \theta \cdot \delta}
$$

A simple protection system is in place to secure the upper and lower limits of the storage tank by on-off-switching of the biogas influx and the outflow to the generators, respectively.

\section{Combined Heat and Power Plant Modelling}

CHP units may be structured from two perspectives: electricity-led and heat-led. These perspectives define the main and by-product of the generation, where the former definition is foremost prevalent in power system operations. Denmark has around $670 \mathrm{CHP}$ plants in operation, outperforming traditional separated generation in terms of energy efficiency by far [17]. More than $60 \%$ of the Danish district heating demand is currently co-generated with electricity, of which more than half is met by renewable biomass resources.

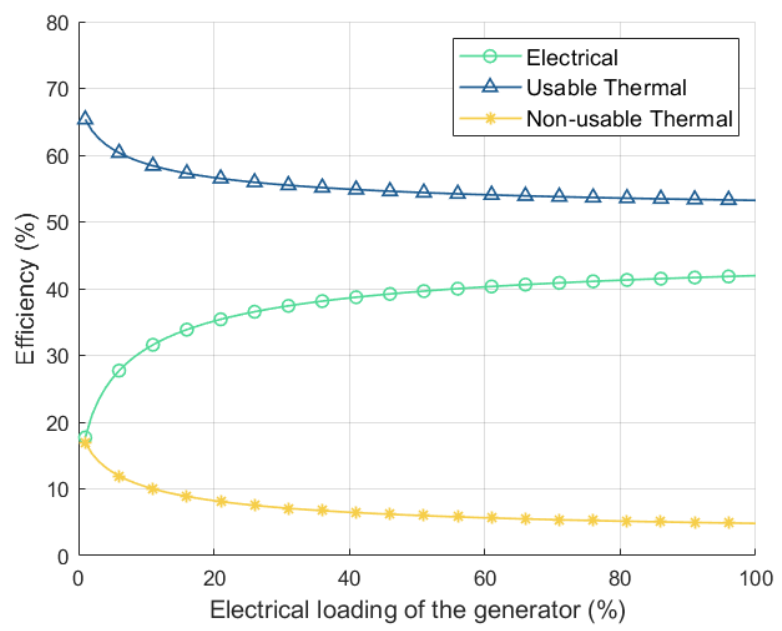

Fig. 3. Efficiencies over different loading states of the CHP unit. 
The two co-generation units considered in this study are of the kind Jenbacher JMS 420, manufactured by GE, each with a nominal electrical output of $P_{e l}^{\max }=1497 \mathrm{~kW}$ el and thermal output of $P_{t h}^{\max }=1882 \mathrm{~kW}$. Under full load biogas operation of one generator, the electrical and thermal efficiencies amount to $42.3 \%$ and $53.2 \%$, respectively, leading to a full load heatto-power-ratio of 1.257. Figure 3 visualizes the electrical and thermal efficiency response over the part-loading states of one generator fitted based on its technical data sheet. For the characterization of the electrical part-load efficiency curve, a power function with rational exponents of the following form has been applied

$$
\eta_{e l}\left(P_{e l}\right)=0.1+\gamma \cdot \frac{\left(P_{e l} / P_{e l}^{\max }\right)^{\alpha}}{\left(P_{e l} / P_{e l}^{\max }\right)^{\alpha}+\beta^{\alpha}}
$$

where $\alpha=0.7012, \beta=0.0662, \gamma=0.3671$, and $P_{e l} / P_{e l}^{\max } \in[0,1]$. The thermal part-load efficiency $\eta_{t h}\left(P_{e l}\right)$ is further described as a function of the electrical efficiency $\eta_{e l}\left(P_{e l}\right)$, as defined in (7).

$$
\eta_{t h}\left(P_{e l}\right)=0.742-0.5 \cdot \eta_{e l}\left(P_{e l}\right)
$$

Even under part-load operation, the overall efficiency of the generators stays high due to a relative increase in recoverable heat which counterbalances the steep decrease in electrical efficiency at low loadings [18].

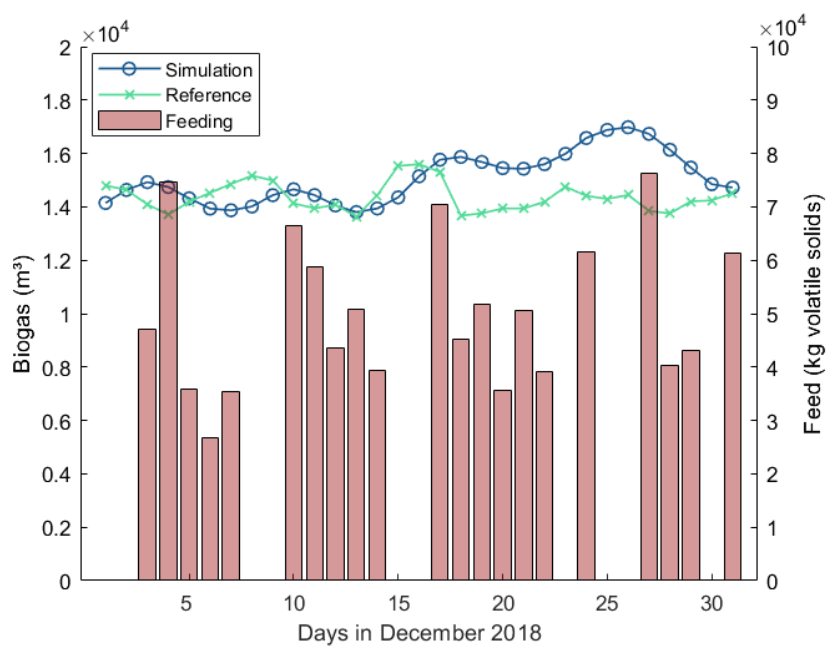

Fig. 4. Daily biogas production rates from the simulation (blue) and reference measurements (green).

\section{Auxiliary Energy Consumption of the Biogas Complex}

Biogas power plants are themselves energy-intensive sites. From an electrical point of view, the permanent utilization of pumps, mixing and stirring machines as well as CHP control units amounts to a significant share of the own electricity production. References [19] and [20] report an auxiliary electrical energy consumption of biogas plants of around 9\%. For the here examined biogas plant, a value of $12.36 \%$ was found to be more precise. In terms of heat that is needed for the pretreatment of the incoming manure and for keeping the reactor tanks of the anaerobic digestion process at stable temperatures of around $38^{\circ} \mathrm{C}$, the thermal self-consumption of a biogas plant is outlined in [20] to be at about $45 \%$.

\section{RESUlts}

The model presented in this work is validated against data from Bornholm's Bioenergi biogas plant. The data set consists on the input side of the daily fed amount of manure, and on the output side of daily values for the produced amount of biogas and generated electricity as well as the monthly heat generation. Additionally, hourly data values from the biogas distribution network feeder are taken as reference electrical setpoints in the CHP unit. The model is implemented in the Matlab-Simulink environment for the whole month of December 2018 in a secondly resolution. The simulation results are subsequently aggregated to daily values for a comparison with the daily reference measurements.

\section{A. Validation Against Real Production Data}

Figure 4 plots the daily biogas production from the simulation (in blue) alongside the plant's reference measurements (in green) on the primary axis. On the secondary axis, the amount of the feeding instances throughout the month is reported. From the figure, it can be seen that the biogas production is matching the daily measurements well in magnitude, although not all dynamics are captured with highest accuracy. This might be due to neglecting the biochemical reactions in the fermenter in detail. The largest deviation between the simulated and the measured production (overshoot on December $27^{\text {th }}$ ) amounts to $20.82 \%$. However, especially for the days in the beginning of the month, the deviation is well in between \pm 5 $10 \%$ in relation to the real-life measurements. The mean value of the deviation in absolute terms is $7.73 \%$ for the simulated month.

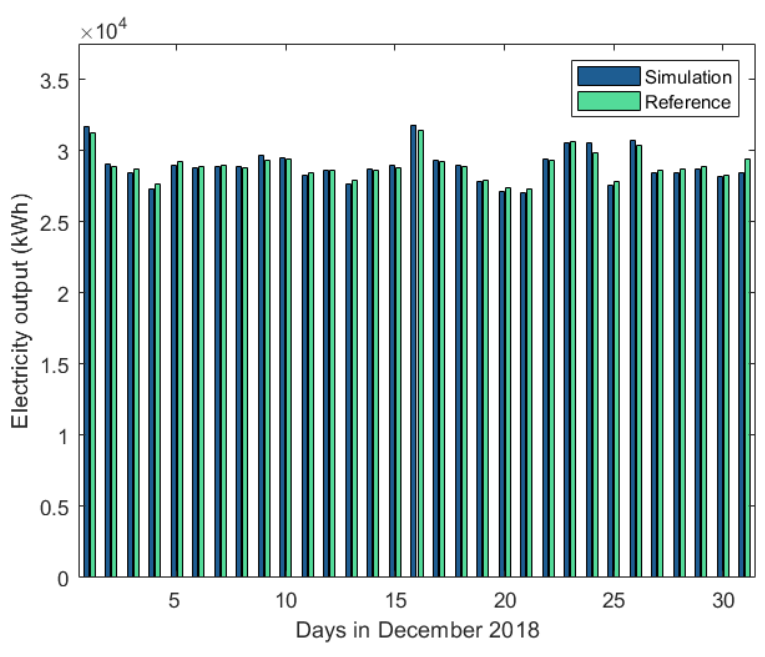

Fig. 5. Daily electricity generation from the simulation versus the historical measurements.

In terms of electrical generation, Figure 5 visualizes the daily results from the simulation (in blue) versus the reference 
measurements of the plant (in green). The model is clearly able to supply the referenced setpoints from the distribution network feeder, upscaled by the auxiliary electrical selfconsumption of the power plant and adjacent offices including all parasitic losses. The simulated daily electrical energy output aligns well to the daily on-site reference measurements. The mean absolute difference for the reported days in December 2018 amounts to $0.78 \%$. For the thermal output, only one measurement of $637 \mathrm{MWh}_{\mathrm{th}}$ for the month of December 2018 is available from the biogas plant for comparison. The simulation obtains a value of $649.7 \mathrm{MWh}_{\text {th }}$, thereby slightly overestimating the reference heat production from the biogas plant by $1.99 \%$. Thus, only small deviations in terms of electrical and thermal output may be reported. These might be due to not accounting for a detailed and complete auxiliary consumption pattern of plant.

\section{B. Assessment of Flexibility Potential}

Biogas co-generation plants entail manifold flexibility options: The gas storage is the central entity for decoupling the different process dynamics and their mutual dependence. For the examined biogas plant, a full storage tank of $2500 \mathrm{~m}^{3}$ biogas provides four hours of one generator's nominal electricity production at $P_{e l}^{\max }=1497 \mathrm{~kW}$ el. In this way, foregone delays in the logistic chains of manure delivery may be (slightly) attenuated. In addition, the composition of the slurry may be modified to some degree in accordance with the medium-term scheduling of the power plant. From an annual perspective, by storing and pointedly utilizing silage or secondary crops, the biogas production may be increased or decreased in a seasonal schedule. To this end, the feeding management of the anaerobic digestion is an important task for exploiting the flexibility potential, see [16] for a discussion. Furthermore, the internal processes connected to the electrical and thermal selfconsumption of the plant leave room for short-term balancing actions. Especially in the context of hybrid power plants, the heat uptake for the digestion processes may help unburden the electrical network without spilling renewable generation, albeit requiring additional hardware.

\section{CONCLUSiON}

In this paper, a biogas power plant model is presented entailing the most relevant dynamics of the anaerobic digestion, gas storage, CHP units and auxiliary self-consumption. The model is tailored to and validated against historical data from a 3-MW biogas plant on Bornholm. The simulation results show that it is capable of following hourly reference power setpoints, while at the same time matching electrical and thermal energy outputs of the plants with high accuracy. Deviations in the simulated daily biogas production are mainly due to the approximation of biochemical reactions and their sensitivities in the digestion process. Future research should address a higher modelling detail of these and the thermal auxiliary consumption of the plant. Furthermore, the paper gives a detailed overview on the biomass potential of the island, as well as a flexibility assessment of entailed biogas operations.

\section{REFERENCES}

[1] N. Scarlat, J.-F. Dallemand, and F. Fahl, "Biogas: Developments and perspectives in Europe,” Renew. Energy, vol. 129, pp. 457-472, 2018, doi: 10.1016/j.renene.2018.03.006.

[2] M. Saeed, S. Fawzy, and M. El-Saadawi, "Modeling and simulation of biogas-fueled power system," Int. J. Green Energy, vol. 16, no. 2, pp. 125-151, 2019, doi: 10.1080/15435075.2018.1549997.

[3] T. Gabderakhmanova, J. Engelhardt, J. M. Zepter, T. M. Sørensen, K. Boesgaard, H. H. Ipsen, and M. Marinelli, "Demonstrations of DC microgrid and virtual power plant technologies on the Danish Island of Bornholm," 2020 Proceedings of the 55th International Universities Power Engineering Conference (UPEC), pp. 1-6, Torino, 1-4 Sep. 2020.

[4] Bornholms Regionskommune, Welcome to Bornholm, Bright Green Island. [Online]. Available: http://www.brightgreenisland.dk/Sider/InEnglish.aspx (accessed: Apr. 14 2020).

[5] Central Husdyrregister 2018. [Online]. Available: http://miljoegis.mim.dk/cbkort?profile=jordbrugsanalyse (accessed: May 4 2020).

[6] Federal Environment Ministry Germany. Ordinance on the generation of electricity from biomass. [Online]. Available: https://www.bmu.de/fileadmin/bmuimport/files/english/pdf/application/pdf/biomasse_verordnung_en_bf.pdf (accessed: May 4 2020).

[7] Affaldsdatasystemet Danmark. [Online]. Available: https://mst.dk/affaldjord/affald/affaldsdatasystemet/ (accessed: May 4 2020).

[8] B. K. Ahring, Biomethanation I: Perspectives for anaerobic digestion in: Adv. Biochem. Eng. Biot. Berlin, London: Springer, 2003.

[9] I. Angelidaki, D. Karakashev, D. J. Batstone, C. M. Plugge, and A. J. M. Stams, "Biomethanation and its potential," Methods Enzymol., vol. 494, pp. 327-351, 2011, doi: 10.1016/B978-0-12-385112-3.00016-0.

[10] J. Palanichamy and S. Palani, "Simulation of anaerobic digestion processes using stochastic algorithm," J. Environ. Health Sci., vol. 12, no. 1, p. 121, 2014, doi: 10.1186/s40201-014-0121-7.

[11] N. Kythreotou, G. Florides, and S. A. Tassou, "A review of simple to scientific models for anaerobic digestion," Renew. Energy, vol. 71, pp. 701-714, 2014, doi: 10.1016/j.renene.2014.05.055.

[12] C. Rosen, D. Vrecko, K. V. Gernaey, M. N. Pons, and U. Jeppsson, "Implementing ADM1 for plant-wide benchmark simulations in Matlab/Simulink," Water Sci. Technol., vol. 54, no. 4, pp. 11-19, 2006, doi: 10.2166/wst.2006.521

[13] J. M. Triolo, A. J. Ward, L. Pedersen, and S. G. Sommer, "Characteristics of animal slurry as a key biomass for biogas production in Denmark," in Biomass Now - Sustainable Growth and Use, M. D. Matovic, Ed.: InTech, 2013.

[14] V. Córdoba, M. Fernández, and E. Santalla, "The effect of substrate/inoculum ratio on the kinetics of methane production in swine wastewater anaerobic digestion," Environ. Sci. Pollut. Res., vol. 25, no. 22, pp. 21308-21317, 2018, doi: 10.1007/s11356-017-0039-6.

[15] H. M. Lo et al., "Modeling biogas production from organic fraction of MSW co-digested with MSWI ashes in anaerobic bioreactors," Bioresour. Technol., vol. 101, no. 16, pp. 6329-6335, 2010, doi: 10.1016/j.biortech.2010.03.048

[16] K. Svensson, L. Paruch, J. C. Gaby, and R. Linjordet, "Feeding frequency influences process performance and microbial community composition in anaerobic digesters treating steam exploded food waste," Bioresour. Technol., vol. 269, pp. 276-284, 2018, doi: 10.1016/j.biortech.2018.08.096.

[17] Danish Energy Agency, A progressive way to cogenerate heat and power. [Online]. Available: https://ens.dk/sites/ens.dk/files/Globalcooperation/chp.pdf (accessed: Apr. 14 2020)

[18] F. R. Spellman, Water \& wastewater infrastructure: Energy efficiency and sustainability. Boca Raton, FL: CRC Press, 2013.

[19] H.-J. Naegele, A. Lemmer, H. Oechsner, and T. Jungbluth, "Electric energy consumption of the full scale research biogas plant "Unterer Lindenhof": Results of longterm and full detail measurements," Energies, vol. 5, no. 12, pp. 5198-5214, 2012, doi: 10.3390/en5125198.

[20] A. Akbulut, "Techno-economic analysis of electricity and heat generation from farm-scale biogas plant: Çiçekdağı case study," Energy, vol 44 , no. 1 , pp. 381-390, 2012, doi: 10.1016/j.energy.2012.06.017. 